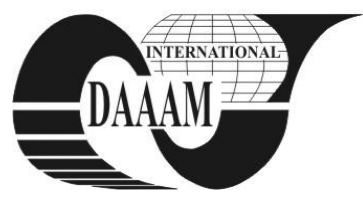

Annals of DAAAM for 2011 \& Proceedings of the 22nd International DAAAM Symposium, Volume 22, No. 1, ISSN 1726-9679 ISBN 978-3-901509-83-4, Editor B. Katalinic, Published by DAAAM International, Vienna, Austria, EU, 2011 Make Harmony between Technology and Nature, and Your Mind will Fly Free as a Bird Annals \& Proceedings of DAAAM International 2011

\title{
APPLICATION METHOD OF AUGMENTED REALITY INCLUDING FEM TO MANUFACTURING SYSTEM
}

\author{
PARK, H[ong] S[eok] \& PARK, J[in] W[oo]
}

\begin{abstract}
Many computer science and manufacturing companies have been studying the AR (Augmented Reality) technology as a new human-machine interface with the development of VR (Virtual Reality) technologies. However, recent researches related with $A R$ are inclined to the accuracy of image registration and the object tracking. Moreover, Application field is limited such as a mobile application. And the development of the CAE simulation interface by using AR is not a common research part. In this research, application method of augmented reality with FEM to manufacturing system is introduced. And the FEM module for the simulation test bed is designed and implemented.
\end{abstract}

Key words: augmented reality, FEM module, manufacturing system, digital manufacturing

\section{INTRODUCTION}

Nowadays, the global market requires shorter life-cycle of products to fulfill the diverse demands of customers. Many manufacturing companies have researched VR based digital manufacturing technologies to survive in the turbulent and competitive market(Park et al., 2007).

For this reason VR is used to analyze the static and dynamic behavior of system or product. However, most of methods and software for digital manufacturing require the perfect 3D models of the whole system or the whole product in virtual environment to represent the target system and surrounding environment. Some manufacturing companies which realize the weaknesses of VR based digital manufacturing technologies have been studying AR technology as new interface between man and machine(Bimber et al., 2008; Ong et al, 2003; Günter et al, 2005)

The ambitious goal of AR is to create the sensation that virtual objects are present in the real world. To achieve the effect, software combines VR elements with the real world. Obviously, AR is most effective when virtual elements are added in real time. Because of this, AR commonly involves augmenting $2 \mathrm{D}$ or $3 \mathrm{D}$ objects to a real-time digital video image. AR technology can remarkably reduce the modeling work, because it uses the real environment to design and to plan manufacturing systems(Park et al., 2008).

However, recent researches related with $\mathrm{AR}$ are inclined to the accuracy of image registration and the object tracking. Moreover, Application field is limited such as a mobile application. And the development of the CAE simulation interface by using AR is an unusual research part(Kim et al., 2010).

Conventional 3D virtual simulators can not animate including real visualization such as dynamic bending displacement of virtual robot arms in manufacturing system. Because of this reason, many researchers are studying about calibration technology of virtual object in 3D simulation system.

In this research, application method of augmented reality with FEM to manufacturing system is introduced and the module for FEM is designed and implemented. Finally, the usability of the FEM module bed based on AR is evaluated.
Moreover, if this research result and the conventional 3D virtual simulation technology are combined, the application fields with AR technology might be diffused dramatically.

\section{DESIGN AND IMPLEMENTATION OF FEM MODULE IN ORDER TO INTEGRATE WITH AR}

Fig. 1. illustrates the architecture of AR system with FEM module. And the core development tool is MFC (Microsoft Function Class) based on $\mathrm{C}++$. The image data from a camera device is processed in video interface for the marker tracking. The video interface converts the video image stream into noncalibrated BGR24 image. Then the tracking function calculates continuously coordinate data of the markers to detect location of each marker. The basic coordinate system for positioning virtual objects is established through the matching procedure between the information of the marker database and the input data of the user interface. The rendering function performs generating and removing of virtual objects with calculated coordinate data. Also, the coordinate transform of virtual objects is executed by using three translations data, three rotations data and three scales data.

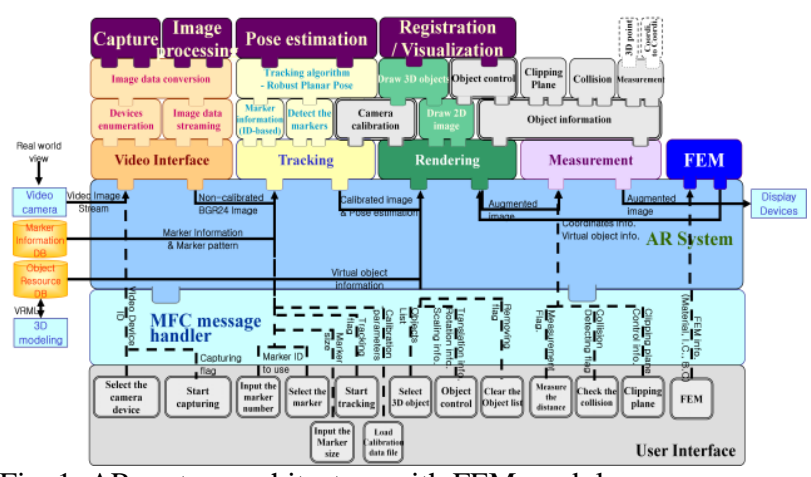

Fig. 1. AR system architecture with FEM module

Fig. 2. is internal structure of FEM module. FEM module recognizes coordinates of the $\mathrm{AR}$ system then the analysis model such as a beam model is selected. After this step, analysis method is selected and simultaneous equations are solved by using $\mathrm{K}$ matrix. And the result values of the simultaneous equations are transmitted to the rendering module. These data will be used to display virtual elements after mathematical analysis such as displacement of the beam element.

\section{EVALUATING OF THE IMPLEMENTED SYSTEM}

The displacement of the beam elements can be calculated with high precision. And this result is applied into the developed system to display bending of beam and user can recognize and find out displacement and also the stress of the beam at real environment(Fig. 3). After this procedure, we 
evaluate usability of the developed FEM module. In order to achieve accuracy of the result data, commercial FEM tool (Abaqus) is used with same conditions such as material properties, initial condition and boundary condition.

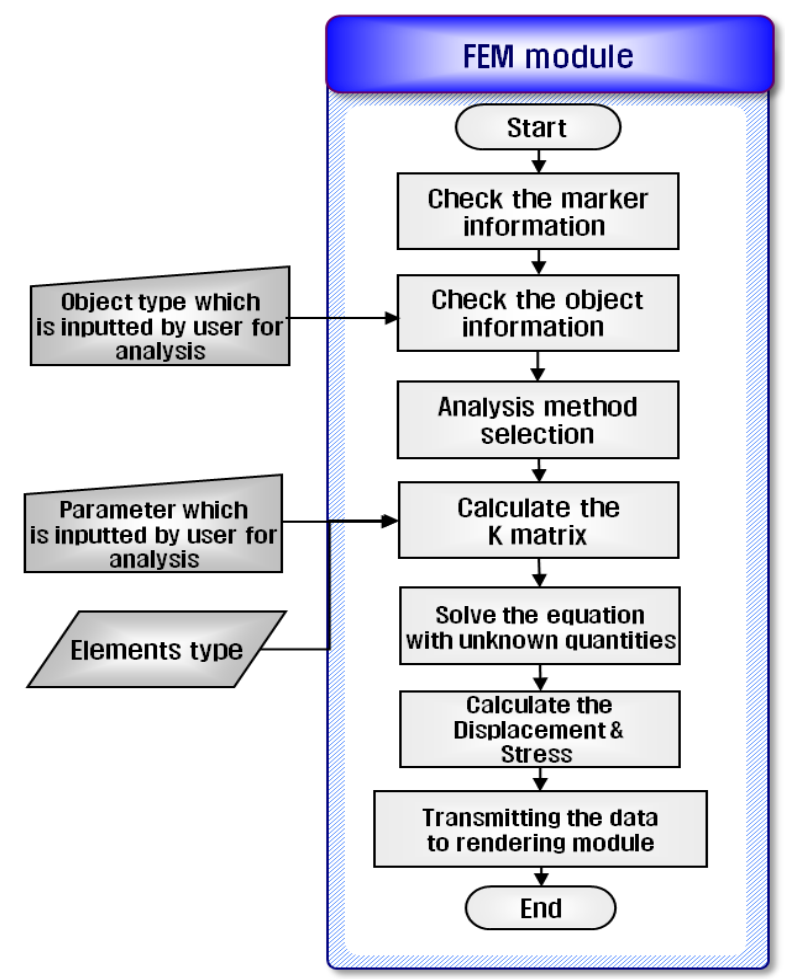

Fig. 2. FEM module for the simulation test bed

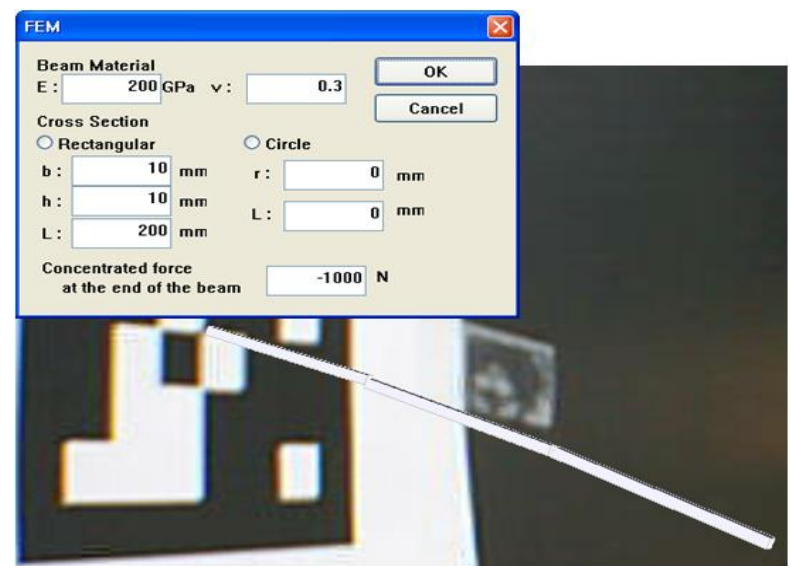

Fig. 3. 3D displacement result of beam elements at AR system

Used material properties and conditions are as follow

$$
\mathrm{E}=2 \mathrm{GPa}, \nu=0.3
$$

Element type: beam

Cross section: square

Size: $\operatorname{Lxbxh}=600 \times 10 \times 10 \mathrm{~mm}$

Initial condition: Cantilever

Boundary condition: concentrated force at the end of the cantilever (force range: $100 \mathrm{~N} \sim 1000 \mathrm{~N}$ )

We divide the cantilever into three elements and it has four nodes. And the system calculates displacement of the cantilever. Tab. 1. shows analysis result of developed system and commercial FEM tool. Tolerance is nearly $1 \mathrm{~mm}$ between developed system and commercial FEM tool. From this result, the developed FEM module with AR has usability to apply into the manufacturing environment such as dynamic bending displacement of virtual robot arms without any calibration work.

\begin{tabular}{|c|c|c|c|c|}
\hline \multirow{2}{*}{ Force $(\mathrm{N})$} & \multicolumn{2}{|c|}{$\begin{array}{c}\text { developed AR } \\
\text { System }\end{array}$} & \multicolumn{2}{c|}{$\begin{array}{c}\text { commercial FEM } \\
\text { tool (Abaqus) }\end{array}$} \\
\hline \multirow{4}{*}{-100} & Node & $\begin{array}{c}\delta \mathrm{y} \\
(\mathrm{mm})\end{array}$ & Node & $\delta \mathrm{y}(\mathrm{mm})$ \\
& 1 & 0 & 1 & $-100 . \mathrm{E}-36$ \\
& 2 & -6.40002 & 2 & -6.30894 \\
& 3 & -22.4000 & 3 & -22.2179 \\
& 4 & -43.2001 & 4 & -42.9268 \\
\hline \multirow{5}{*}{-200} & 1 & 0 & 1 & $-200 . \mathrm{E}-36$ \\
& 2 & -12.8000 & 2 & -12.6179 \\
& 3 & -44.8001 & 3 & -44.4358 \\
& 4 & -86.4003 & 4 & -85.8536 \\
\hline-500 & 1 & 0 & 1 & $-500 . \mathrm{E}-36$ \\
& 2 & -32.0001 & 2 & -31.5447 \\
& 3 & -112.000 & 3 & -111.089 \\
& 4 & -216.000 & 4 & -214.634 \\
\hline \multirow{5}{*}{-1000} & 1 & 0 & 1 & $-1 . \mathrm{E}-33$ \\
& 2 & -64.0002 & 2 & -63.0894 \\
& 3 & -224.000 & 3 & -222.179 \\
& 4 & -432.001 & 4 & -429.268 \\
\hline
\end{tabular}

Tab. 1. Result of developed system and commercial FEM tool

\section{CONCLUSION}

In this research application method of augmented reality with FEM to manufacturing system is introduced. And each functional module is designed and implemented. Especially in order to connect AR technology with FEM, the FEM module is developed. Based on FEM module, user can check bending displacement and stress of the 3D virtual element such as cantilever. To prove usability and applicability of the developed system, we select simple model such beam element. Analysis result is almost same after calculating process at the developed system and commercial FEM tool. From this result, this developed system can be used at various environments especially manufacturing system implementation with AR technology.

\section{ACKNOWLEDGEMENTS}

This research was supported by the Ministry of Knowledge Economy, Republic of Korea under the Configurable MES Platform for Productivity Innovation \& Process Optimizing of SME.

\section{REFERENCES}

Bimber, O. \& Raskar, R. (2008), Spatial Augmented Reality Merging Real and Virtual Worlds, A K Peters, pp.1-12, 2008

Günter, W. \& Emmerich , S.(2005), Digital Planning Validation in Automotive Industry, Computers in Industry, Vol. 56, 93-405

Kim, S. J. \& Dey, A. K. (2010).AR interfacing with prototype 3D applications based on user-centered interactivity, Computer-Aided Design, Vol. 42, No. 5, 373-386, ISSN: 0010-4485

Ong, S. K. \& Nee, A. Y. C.(2003), Virtual and Augmented Reality Applications in Manufacturing, Springer

Park, H. S. \& Lee, G. B. (2007). Development of digital laser welding system for automobile side panels. Int. Jr. of Automotive Technology, Vol. 8, No. 1, 83-91

Park, H. S.; Choi, H. W. \& Park, J. W. (2008), Implementation of automobile cockpit module assembly system using augmented reality technology. Transactions of NAMRI/SME, Vol. 36, No. 1, 493-500 